\title{
REDUÇÃO DA MAIORIDADE PENAL \\ EM RELAÇÃO AOS CRIMES VIOLENTOS: \\ UMA ANÁLISE ECONÔMICO- \\ COMPORTAMENTAL
}

Julio Cesar Aguiar ${ }^{1}$

Carrel Ypiranga B. Gomes ${ }^{2}$

Benjamin Miranda Tabak ${ }^{3}$

\author{
REDUCTION OF CRIMINAL AGE IN RELATION TO \\ VIOLENT CRIMES: AN ECONOMIC-BEHAVIORAL \\ ANALYSIS
}

RESUMO: O artigo se propõe a investigar, sob uma perspectiva econômica comportamental, a relação entre as taxas de encarceramento e gastos com a segurança pública e a diminuição dos números de crimes violentos letais intencionais. Compara com a escolha da população brasileira, demonstrada em pesquisa de opinião, pela redução da maioridade penal. A partir disso, defende a ideia de que essa escolha sofre de uma limitação racional que, de acordo com a teoria paradigma, pode ser denominada como um viés de representatividade.

Palavras-chave: Maioridade penal. Taxa de Criminalidade. Análise econômico-comportamental.
ABSTRACT: The article proposes to investigate, from a behavioral economic perspective, the relationship between incarceration rates and public security spending and the reduction of intentional lethal violent crimes. It compares with the choice of the Brazilian population, demonstrated in opinion polls, that defends the reduction of the penal age. From this, it defends the idea that this choice suffers from a rational limitation that, according to the paradigm theory, can be denominated as a representative bias.

Keywords: Criminal majority. Criminal Rates. Economicbehavioral analysis.

\footnotetext{
${ }^{1}$ Doutor em Direito pela Universidade Federal de Santa Catarina e PhD in Law pela University of Aberdeen, UK. Professor da Graduação e do Mestrado em Direito da Universidade Católica de Brasília, atuando na linha de pesquisa Direito, Ciências, Instituições e Desenvolvimento. Pesquisador Colaborador do Instituto de Psicologia da Universidade de Brasília e Procurador da Fazenda Nacional, atuando na Consultoria de Assuntos Financeiros do Ministério da Fazenda.

${ }^{2}$ Universidade Católica de Brasília..

${ }^{3}$ Doutor pela Universidade de Brasília (2000). Atualmente é professor do programa de pós-graduação stricto sensu em Direito da Universidade Católica de Brasília e Consultor Legislativo do Senado Federal. Editor-chefe da revista Economic Analysis of Law Review e editor associado de revistas especializadas nacionais e estrangeiras. Pesquisador $1 c$ do CNPq. Revisor de projetos de fomento do CNPq e CAPES.
} 


\section{INTRODUÇÃO}

No ano de 2015, a Câmara dos Deputados aprovou o Projeto de Emenda Constitucional n.o 171 de 1993, ainda pendente de análise pelo Senado Federal, que reduz a maioridade penal de dezoito para dezesseis anos. No mesmo ano de 2015 , o instituto Data Folha realizou pesquisa de opinião sobre a redução da maioridade penal e, como resultado dessa pesquisa, aferiu-se que $87 \%$ da população possuía opinião favorável à dita redução. Diante desse quadro, perguntamos se essa escolha seria do melhor interesse da sociedade.

Considerando a ideia de que a Análise Econômica Comportamental lida com o ser humano real e suas limitações, basicamente ligadas a racionalidade, força de vontade e de interesse próprio, propõe-se a uma investigação sobre a atitude de grande parte da população brasileira em apoiar a redução da maioridade penal, exatamente sob a ótica dos vieses estudados pela teoria.

Segundo Kahneman e Tversky (1974), é comum que decisões sejam tomadas de acordo com uma avaliação subjetiva da probabilidade, sem que de fato tal avaliação seja correta. Normalmente tais julgamentos se baseiam em uma validade limitada e processados por regras heurísticas.

Uma das heurísticas discutidas por Kahneman e Tversky (1974) é a representatividade. De acordo com essa heurística, a julgar pela dessemelhança ou semelhança entre fatores de um problema as pessoas tendem a relacioná-los probabilisticamente. Como exemplo, citam o fato de que por uma descrição da personalidade de um determinado indivíduo as pessoas tendem a atribuir-lhe uma profissão. Mas ao fazerem tal atribuição por representatividade, não consideram, via de regra, a probabilidade a priori de um resultado ou taxa base de resultados. No caso específico do exemplo dado pelos autores, as pessoas desprezaram o fato de que uma determinada profissão tem muito mais integrantes na população do que outra. Ativeramse, deste modo, apenas às características de personalidade e nas semelhanças que 
acreditaram ter o indivíduo hipotético para com a profissão escolhida, mesmo havendo muito mais pessoas na população desempenhando outras profissões.

$\mathrm{Na}$ investigação a que nos propomos, quase nove em cada dez brasileiros, segundo pesquisa da Data Folha, apoiam a redução da maioridade penal. No entanto, a se considerar dados do IPEA, da segurança pública e o relatório da Comissão Parlamentar de Inquérito da Câmara dos Deputados, que investigou denúncias junto ao sistema penitenciário, pode-se concluir que os gastos com os indivíduos no sistema educacional são algumas vezes menores do que os gastos com indivíduos no sistema penitenciário.

Estudos sobre investimentos em educação fundamental (DONOHUE; SIEGELMAN, 1998), por outro lado, revelaram que crianças que se submeteram a um programa de educação infantil de qualidade tiveram uma probabilidade menor de entrarem em conflito com a lei. Além disso, segundo o posicionamento defendido por Flora (2004), as recompensas psicológicas advindas do comportamento criminoso ativam os mesmos mecanismos das recompensas pelo uso de drogas.

Por outro lado, estatisticamente, a taxa de encarceramento no Brasil é particularmente alta, sem que o número de crimes violentos letais intencionais ou a sensação de segurança da população tenham apresentado significativas melhoras. Em vista desses argumentos nos propomos a uma investigação não de uma política criminal eficiente, mas que analise a escolha da população do ponto de vista econômico comportamental, escolha esta, segundo nossos argumentos, decorrente de um viés limitador da racionalidade.

Desenvolveremos uma análise, segundo a qual, a escolha pela redução da maioridade penal além de mais cara, pelos números da segurança pública, não conduziriam ao resultado esperado de redução dos índices de crimes violentos letais intencionais cometidos por adolescentes com idade entre dezesseis e dezoito anos, até porque a punição não se tem demonstrado eficaz para coibir crimes cometidos por adultos. A ideia de punição e retribuição de um crime é diretamente ligada a ideia de desencorajamento de comportamentos criminosos futuros. Contudo, como se procurará demonstrar, as reações psicológicas dos indivíduos adeptos a cometimentos reiterados de 
ações delituosas, revelam de pouca valia a visão exclusivamente punitiva como solução de reabilitação.

Não se olvida que o crime seja uma escolha racional do ponto de vista do criminoso (MADJD-SADJADI, 2103, cap. 2), no entanto, o que se levanta como hipótese é que a escolha punitiva da sociedade, por si só, e de acordo com os estudos comportamentais que se alia, não é necessariamente a melhor opção para tornar a escolha de cumprir a lei, aos olhos do criminoso ou do adolescente infrator, mais racional.

\section{PARADIGMA ECONÔMICO E ECONÔMICO COMPORTAMENTAL}

Na década de setenta do século XX, em oposição a visão autônoma do direito em relação as demais disciplinas, surgiram alguns movimentos, dentre os quais a Análise Econômica do Direito que propõe a análise do Direito sob a perspectiva econômica (ALVAREZ, 2014). Nessa perspectiva, portanto, o direito passa a ser visto em uma relação interdisciplinar com os institutos da microeconomia. A visão puramente positivista do Direito, ao longo da história, como bem observa Posner (2009, p. 155-179), revelou-se polêmica. Em um resgate histórico do período em que subsistiu o terceiro Reich na Alemanha, até uma análise sobre a conivência jurídica com a escravidão, o autor põe, como o próprio título do capítulo em referência sugere, amostra de uma crise sobre a moralidade do Direito. A visão meramente positivista, ao menos por essa perspectiva, tem tido em momentos variados da história, problemas significativos para dar justificativas morais. E, por isso, em grande medida, uma visão multidisciplinar da análise do Direito, seja econômica ou não, acabou por encontra seu desenvolvimento.

Contudo, em economia parte-se do pressuposto que os agentes econômicos busquem o que mais Ihes favorece. Por exemplo, o comprador tenta adquirir o melhor produto pelo menor preço e o vendedor tenta diminuir ao máximo o valor do produto e vendê-lo pelo maior preço possível. A isso dá-se o nome de maximização. Os agentes econômicos, portanto, buscam o máximo de satisfação possível e isso é parte dos modelos econômicos (COOTER; ULEN, 2010, p. 36). Há, para alguns, a visão de que a conjunção da análise econômica e o direito somente pode se dar pelo pressuposto de racionalidade dos indivíduos como, por exemplo (HOVENKAMP, 1991). 
No entanto, a ideia do homo economicus quando confrontada com as escolhas diárias das pessoas comuns revela significativas distorções. Daniel Kahneman, em sua obra Rápido e Devagar, descreve uma série de experimentos dos quais conclui que o ser humano não age, obrigatoriamente, de maneira racional. A escolhas que fazemos, sofre não raras vezes, de vieses importantes e que, ao contrário do que a teoria da escolha racional sugere, nem sempre atendem aos nossos melhores interesses.

A ideia central da economia comportamental, portanto, é o estudo das pessoas comuns e não de um homo economicus abstrato ou hipotético (JOOLS; SUSTEIN; THALER, p. 1476). De acordo com essa perspectiva é possível identificar-se três limites às escolhas, a saber; limite a racionalidade, a força de vontade e ao interesse próprio. E cada uma dessas limitações demonstra como as pessoas se distanciam dos padrões do modelo econômico tradicional (JOOLS; SUSTEIN; THALER, p. 1476).

As limitações racionais partem por princípio que os seres humanos possuem capacidades intelectuais limitadas e, por isso, buscam atalhos mentais para resolver problemas, chegar a conclusões e tomar suas decisões. Entretanto, a utilização de tais atalhos afasta sistematicamente as pessoas das escolhas racionais, como presumido pelos padrões da teoria econômica e, consequentemente, da utilidade esperada. Assim como julgamentos não enviesados são insuficientes para descrever o comportamento humano, a teoria da utilidade esperada também não descreve satisfatoriamente as decisões que tomamos (JOOLS; SUSTEIN; THALER, p. 1477). Argumento contrário a irracionalidade como característica inerente do ser humano é trazido por Posner (1998).

Em oposição a teoria da utilidade esperada, Kanhneman e Tversky (1979) desenvolveram a teoria do prospecto, da qual enumeramos dois pontos fundamentais, a saber; ponto de referência e aversão ao risco. O primeiro, segundo a teoria em comento, diz que as pessoas avaliam as consequências das escolhas feitas normalmente comparando com o estado em que se encontravam no momento da escolha, isto é, considerando o objetivo que almejam e o estado que se encontram, os indivíduos irão analisar as perspectivas de ganhos ou perdas a partir desse ponto. Pela conclusão acerca da aversão a perda, ou função do valor, a teoria defende que as pessoas dão mais importância às perdas do que aos ganhos, ou seja, na percepção da maioria das pessoas as perdas têm uma 
grandeza maior do que os ganhos. Por exemplo, se um investidor avalia que os riscos de perda em uma transação no mercado financeiro são de $\$ 1000,00$ e as possibilidades de ganho também são da ordem de $\$ 1000,00$, pela teoria do prospecto as perdas parecerão, ao investidor, mais aversivas do que os ganhos motivadores.

Antes de desenvolverem o estudo acima mencionado, Kahneman e Tversky (1974), procuraram explicar que os julgamentos das pessoas são baseados em probabilidades. No entanto, tais probabilidades são construídas a partir de dados sem validade. No julgamento por representatividade, os autores defendem que as semelhanças entre dois fatores são determinantes para que as pessoas os correlacione. Em um conceito desenvolvido por Kahneman e Tversky (1983), a representatividade seria uma avaliação de grau de correspondência, seja entre uma amostra da população, seja entre um instância e um categoria ou entre um modelo e um resultado, sendo este último, aliás, mais comum.

Para julgar se de um determinado processo advirá um resultado específico, pela heurística da representatividade, como mencionado na introdução, as pessoas buscarão semelhanças entre os dois o suficiente para julgar se de fato podem concluir que de um se obterá como resultado o outro. Por exemplo, se alguém é chamado a dizer qual a profissão de uma pessoa e tem acesso a informações sobre a personalidade dessa mesma pessoa, pela heurística da representatividade, esse alguém tentará adequar a profissão da pessoa às características da personalidade dada por similaridade. E não considerará, por exemplo, que a profissão escolhida como provável quase possui muito menos integrantes do que outras na população.

Essa ilusão de validade, conforme designam os próprios autores, acontece quando a similaridade usada para correlacionar o dado inicial com o resultado não é válido. Mesmo que as pessoas tenham ciência dos dados válidos e, a princípio mais confiáveis, ainda segundo a heurística da representatividade, continuarão se baseando em similaridades para chegar às conclusões acerca das probabilidades (SCHWARZ; VAUGHN, 2002, kindle, posição 2892). Os autores citam o exemplo dos psicólogos que manifestam grande confiança nas entrevistas de seleção, quando na verdade, a literatura acerca do tema revela o baixo índice de eficácia do método (KAHNEMAN'TVERSKY, 1974). Estudo empírico realizado por Kahneman e Frederick (2002) valida a hipótese acima e destaca que mesmo 
com dados importantes disponíveis para a uma resposta, em grande parte dos casos, tais dados foram ignorados. Outros estudos interessantes sobre a representatividade, a fim de revalidá-la com resultados empíricos são (BAR-HILLEL; NETER, 1993) sobre a violação de regra de probabilidades em função da representatividade;

Kahneman (2003) defende a ideia de que existem dois sistemas ou duas formas de pensar, a saber, a de número 1 e a de número 2. A primeira forma é ligada a juízos rápidos e intuitivos em que as pessoas se utilizam de atalhos mentais para chegar a uma conclusão acerca de um problema proposto ou uma decisão que tenham de tomar. Normalmente as pessoas usam o sistema número 1 , mais rápido e menos dispendioso em termos de energia. No entanto, o uso de atalhos mentais ou shortcuts conduzem a conclusões enviesadas. O estudo desses vieses chegou, mais especificamente ao que no presente trabalho nos interessa, a conclusão sobre a representatividade. Ainda segundo Kahneman, não existe uma teoria geral sobre o fenômeno descrito por ele, mas sim uma série de experimentos que, pelos dados empíricos obtidos, apresentam uma forte possibilidade de generalização dos resultados para uma base segura de previsibilidade e formação do modelo do fenômeno. Diante das críticas à teoria da racionalidade, já surgem vozes sobre a necessidade de diminuição das ambições da Análise Econômica do Direito (DOOMEN, 2013).

Em matéria jurídica, é necessário que se diga, que as escolhas sobre a adoção de normas passam pelos impactos que tais normas terão no comportamento humano, de tal sorte que as limitações às escolhas racionais tornam-se de suma importância (JOLLS e SUNSTEIN, 2005). Normalmente as escolhas sobre a regulação, juridicamente falando, são feitas de maneira intuitiva, no que diz respeito aos efeitos que terão sobre o comportamento humano. O modelo econômico comportamental, a seu turno, procura conferir um ponto de apoio científico para as inferências sobre o comportamento humano diante de uma determina norma, considerando, inclusive, as limitações significativas do modelo em que os indivíduos são presumidamente racionais (TOR, 2008, p. 237).

É preciso destacar que experimentos desenvolvidos tem como principal desafio o de fornecer dados confiáveis para que se infira acerca do mundo real. E, mesmo que se considere que os ambientes controlados dos experimentos não se repetem na realidade, o 
fato é que os dados fornecidos pelos experimentos, ainda que contenham essa limitação, são melhores do que a ausência total de dados (LEVITT; LIST, 2007).

\subsection{Análise econômica do crime}

Talvez, ainda hoje, a obra mais relevante acerca da teoria econômica do crime seja a de Becker (1974), segundo ele os envolvidos no fenômeno criminoso, a saber, sociedade, infrator e vítima, comportam-se de acordo com o presumido pela teoria econômica. Isso significa que existe uma avaliação sobre ganhos e perdas, inclusive por parte do criminoso, na tentativa de obter a maior satisfação possível, coincidente com a teoria da escolha racional. De acordo com sua posição (BECKER, 2013, p. 8), a análise econômica pode ser aplicada para a compreensão de qualquer comportamento humano baseando-se, inclusive, na ideia de Bentham (1823) de que o ser humano é governado por dois senhores, o prazer e a dor. De tal forma, é plausível admitir que pela teoria econômica do crime há uma relação funcional entre utilidade e risco. A utilidade da satisfação é calculada em relação ao risco de ser apanhado e sofrer as consequências legal do ato criminoso, normalmente aversivas. Interessante estudo sobre o comportamento criminoso realizado em acordo com essa perspectiva é o de Matsueda (2006).

Becker e Murphy (2009, p. 3), fazem algumas considerações sociais sobre a utilidade e como essas influências incrementam ou não a utilidade marginal e favorecem comportamentos. Os autores, apesar de asseverarem que os economistas modernos não admitem as influências sociais no comportamento, procuram demonstrar que a função de utilidade deve abarcar as variáveis sociais $[U=U(x, y ; S)]$, onde $U$ é a utilidade, $x$ e y são bens de qualquer natureza e S representa as influências sociais. Nessa perspectiva, explicam que em uma abordagem usual a utilidade dependeria exclusivamente de $x$ e $y$, de maneira que a variável S, na perspectiva por eles adotada, passaria a ser função da equação como um todo (BECKER; MURPHY, 2009, p. 8-9). Portanto, a variável S afetará o comportamento desde que influa no aumento ou diminuição da utilidade marginal, ou seja, um aumento da influência social S aumentará a utilidade marginal de $\mathrm{x}$ ou y e, neste ponto, pode-se dizer que $S$ influencia na demanda de x ou y (BECKER ; MURPHY, 2009, p. 8-9). 
Os autores, no entanto, quando descrevem o comportamento delinquente de adolescentes, remetem as influências sociais ao comportamento dos pares. Afirmam ser mais provável que adolescentes cometam crimes com baixas recompensas, embora o custo do crime seja elevado, porque acompanham-se de outros adolescentes que também demonstram um comportamento delinquente, ou cometeriam poucos crimes, embora frente a possibilidades de grandes recompensas, simplesmente porque suas companhias não adotam comportamento de conflito com a lei (BECKER; MURPHY, 2009, p. 135).. Também existem argumentos interessantes sobre o papel da comunidade no cometimento de crimes e a situação de Stress e tensão como correlacionadas a prática criminosa (AGNEW, 1999). As influências sociais, aliás, são também estudadas em relação a comportamentos outros, inclusive com achados interessantes sobre os efeitos positivos que causam na formação da memória (BROWN; SCHAEFER, 2010), nas opiniões políticas no que toca a aprovação ou não de mandatários (BINNING et al., 2015) ou mesmo no aprendizado de vieses (WALTERS; KENDAL, 2013) .

$\mathrm{Na}$ outra ponta, é preciso considerar que a prevenção de crimes com encarceramento e estrutura de persecução redunda em custo. O custo óbvio para o Estado é o montante de dinheiro a ser alocado nessas atividades (BECKER, 1974). Assim, em uma perspectiva da teoria racional, é preciso que os custos do combate ao crime não superem as eventuais perdas que a coletividade sofreria com os crimes eventualmente evitados pelo sistema de punição estatal, a fim de atingir condições ótimas entre o custo do combate ao crime e o ganho com esse combate (BECKER, 1974).

Interessante estudo desenvolvido por Marvell e Moody (1994) encontrou uma elasticidade estimada entre a taxa de encarceramento e diminuição dos índices de criminalidade da ordem 0.16 , ou seja, para $1 \%$ de aumento na população carcerária, apenas $0.16 \%$ de diminuição dos índices de criminalidade. Os dados foram colhidos em quarenta e nove Estados americanos referentes aos anos de 1971 e 1989. Essa relação de eficácia da pena de prisão pode ser utilizada, por exemplo, para planejar o custo da diminuição do cometimento de crimes a um determinado patamar, de acordo com o que o Estado está disposto a gastar. Por exemplo, por esse estudo seria razoável acreditar que 
uma diminuição dos índices de criminalidade na ordem de 50\%, resultaria em um incremento de 312,5\% da população carcerária.

Outros estudos dão conta de uma eficácia maior da pena de prisão em relação a contenção do número de crimes. Segundo seu estudo, Levitt (1995) encontrou uma elasticidade entre 0.30 e 0.40 , a depender da natureza do crime, contra a propriedade no primeiro caso e crimes violentos no segundo. No entanto, o estudo de Levitt é duramente criticado, inclusive acerca de falhas na análise dos dados por Donohue e Siegelman (1998).

A educação integral, no entanto, revela dados bem mais animadores sobre o impacto na redução da criminalidade. Um estudo desenvolvido por Berthelon e Kruger (2011), sobre a realidade chilena, sugere que um aumento de $20 \%$ no sistema de educação integral reduz significativamente não só os índices de criminalidade, mas também o de gravidez na adolescência. Pela pesquisa, um aumento da ordem em comento no sistema de ensino integral, demonstrou-se capaz de uma redução aproximada de $22 \%$ dos crimes contra a propriedade e de $12 \%$ dos crimes violentos. A média de redução de todos os crimes levantada pelos autores foi 17,5\%. Cabe aqui um pequeno parêntese, tão-somente para argumentar acerca dos números de redução da gravidez na adolescência que, segundo o estudo foi de $3 \%$ com o aumento, também de $20 \%$, no sistema de tempo integral de ensino. Aqui cabe o esclarecimento de que no sistema chileno descrito, os alunos têm um acréscimo de $30 \%$ no tempo de permanência na escola (VALENZUELA, 2005).

Estudos outros não só sugerem que investimentos ligados a educação podem reduzir significativamente os índices de criminalidade, inclusive com eficácia superior ao do encarceramento (DONOHUE; SIEGELMAN, 1998), como relacionam níveis de educação com menor envolvimento dos indivíduos em atividades criminosas (BUONANNO; LEONIDA, 2009); (WOLFE et al., 2002). Outros estudos também de interesse sobre os efeitos da educação sobre a redução do crime são (LOCHNER; MORETTI, 2001), (LOCHNER, 2010), este último argumenta sobre o fato de que é crescente o número de evidências de que a qualidade do ensino e, principalmente, a conclusão do ensino médio influem na diminuição de crimes violentos e contra o patrimônio. O mesmo autor também argumenta em outro estudo a correlação de crimes violentos e juventude e reafirma a educação como 
política eficaz para a diminuição desse tipo de crime (LOCHNER, 2004). Há ainda interessante estudo sobre a eficácia das políticas educacionais associadas a outras políticas para a prevenção do crime (SABATES; FEINSTEIN, 2007).

\subsection{Contribuição behaviorista}

A teoria behaviorista foi iniciada por J.B. Watson (1913) e depois desenvolvida por Skinner (1938) e (Skinner, 1954) compreende o comportamento como algo controlado pelo ambiente e pela genética do indivíduo (SKINNER, 2011, p. 208). Em relação ao ambiente, basicamente, são duas as consequências selecionadoras, a saber, punição e reforço. Essa forma de análise ou esquema é denominado de contingência de dois termos (LOPES; MATOS, 1995, p. 33). Por tal compreensão, o indivíduo, após esboçar um comportamento qualquer, percebe uma consequência ambiental que pode ser reforçadora ou punitiva. Ainda por esta perspectiva, enquanto a punição tende a diminuir, o reforço, a seu turno, implica no aumento da frequência do comportamento. Em outras palavras,

punição é consequência do comportamento que reduz a futura probabilidade desse comportamento ou, de forma mais completa, punição é a redução da futura probabilidade de uma resposta específica como resultado de uma entrega imediata de algum estímulo para esta resposta (AZRIN; HOLZ, 1966).

Ainda segundo os autores, é possível que a punição seja efetiva e leve a extinção do comportamento, contudo, dentre as circunstâncias necessárias para o sucesso da operação, defendem que a punição deve se seguir imediatamente ao comportamento que se deseja extinguir. Tal conceito também é utilizado por Todorov (2001). Do outro lado, se um comportamento continua acontecendo em virtude de uma consequência, tal consequência é reforçadora (SCHNEIDER, 2012, p. 20).

Conforme dito alhures, Flora (2004, p. 182) cita estudos que sugerem ser, o comportamento criminosos habitual, reforçado ou psicologicamente recompensado de maneira similar ao de adictos em entorpecentes. Também sugerem os estudos (WOOD et al., 1997) que a recompensa obtida pelo criminoso é endógena e independente das recompensas exógenas, embora conjuntas. De maneira que, em sendo assim, as recompensas são imediatas, ainda durante a prática criminosa. A própria atividade de risco, não só a criminosa, pode ser tida pelo indivíduo como altamente reforçadora. Lyng 
(2014, p. 509), argumenta a partir de uma análise de atividades de risco tomadas voluntariamente com, por exemplo, esportes radicais, que um número significativo de indivíduos se colocam em situações de risco e que a recompensa seria a própria assunção do risco.

Pelos efeitos recompensadores intrínsecos do crime e, portanto, imediatos à prática, é possível entender o porquê de punições serem ineficazes e a dificuldade da reabilitação (FLORA, 2004, p. 182), inclusive afirma Flora (2004, p. 183) que um aumento nos riscos do cometimento do crime, ao invés de reduzir as chances de sua prática, poderia aumentá-la, já que seria mais recompensador ao criminoso a tentativa de cometer o "crime perfeito". Aliás, no que toca a agressividade mais especificamente, há indícios científicos bastante sérios que correlacionam comportamentos agressivos a déficit na produção de neurotransmissores como, por exemplo a serotonina. (BLUM et al., 2000).

Outros estudos, desta vez de neurociência, revelam uma magnitude significativamente maior para o reforço em comparação com a punição. O’Doherty (2001), desenvolveu um estudo que correlacionou as atividades no córtex Orbitofrontal com a magnitude tanto do reforço como da punição. O experimento foi dividido em fases, nas quais os participantes eram colocados em situações de eventuais perdas ou ganhos de quantias de dinheiro variáveis. Por meio de ressonância magnética, os pesquisadores concluíram que as áreas ativadas eram superiores quando o resultado era recompensador (O'DOHERTY et al., 2001). Entre nós, a ideia de que os paradigmas behavioristas são úteis ao Direito, inclusive por considerar este como um indutor de comportamentos, não é nova e vem sendo explorada em uma perspectiva sistêmica por Aguiar (2013).

\section{ESCOLHA PELA REDUÇÃO DA MAIORIDADE PENAL}

O Projeto de Emenda Constitucional n.o 171 de 1993, foi analisado, votado e aprovado em dois turnos pela Câmara dos Deputados no ano de 2015. Pelo projeto, agora pendente de apreciação pelo Senado Federal, a imputabilidade penal passa a existir aos dezesseis anos e não mais aos dezoito anos. No mesmo ano de 2015 , o instituto Data Folha realizou pesquisa de opinião sobre a eventual redução da maioridade penal e, de acordo 
com os resultados de tal pesquisa, oitenta e sete por cento da população brasileira manifestou-se favoravelmente a essa inovação legislativa. ${ }^{4}$

A escolha, portanto, tanto da câmara baixa do parlamento brasileiro, quanto da população vão em um sentido claro de recrudescimento do trato com adolescentes, maiores de dezesseis anos, que entrem em conflito com a lei penal. No entanto, como procuramos demonstrar, é plausível acreditar que tal escolha não seja a que mais atenda aos interesses da sociedade e, numa perspectiva racional da escolha, essa seria fruto de um viés.

Os custos com o sistema carcerário são elevados e, ao mesmo tempo, insuficientes para criar o número de vagas necessárias a fim de abrigar a crescente população de presos. Contudo, os dados sobre os custos reais de cada detento para o Estado ainda não são claros. No ano de 2008 foi elaborado um relatório na Comissão Parlamentar de Inquérito da Câmara dos Deputados, comissão que foi instalada para averiguar a situação do sistema penitenciário brasileiro, segundo o qual o custo aproximado de um preso no sistema penitenciário federal (DEPEN) por mês era, à época, de $\mathrm{R} \$ 1,300,00$ em presídios comuns e de $\mathrm{R} \$ 4,500,00$ em presídios de segurança máxima. A Comissão Parlamentar de Inquérito da Câmara dos Deputados destacou ainda ter encontrado disparidade no custeio de cada detento, encontrando valores que variaram entre $R \$ 500,00$ e $R \$ 1,700,00$ nos Estados, por preso ${ }^{5}$.

Corrigindo o valor de custeio de cada preso no sistema federal fora dos presídios de segurança máxima segundo o INPC, de dezembro de 2008 a janeiro de 2016, e considerando o índice de 58,6293400\%, que aplicado ao valor de $\mathrm{R} \$ 1.300,00$ resulta a quantia de $\mathrm{R} \$ 2.062,18^{6}$ por mês para o custeio de cada detento. Por ano e com valores corrigidos, conclui-se que o gasto seria da ordem de $\mathrm{R} \$ 24.746,16$ por preso.

Por outro lado, os gastos com educação por aluno na rede pública, segundo o INEP ${ }^{7}$, foi de $\mathrm{R} \$ \quad 6.203,00$ em média no ano 2013. Note-se que o gasto referido foi anual e não

\footnotetext{
${ }^{4}$ Pesquisa de Opinião 813812 do instituto Data Folha realizada entre os dias 17 e 18 de junho de 2015, com 2840 entrevistas e margem de erro de $2 \%$ para mais ou para menos em um índice de confiança de $95 \%$.

${ }^{5}$ Relatório final da Comissão Parlamentar de Inquérito do Sistema Penitenciário da Câmara dos Deputados, p. 364.

${ }^{6}$ Cálculo segundo sítio do Banco Central. Disponível em: <https://www.bcb.gov.br/?CORRECAO>

7 Disponível em: http://portal.inep.gov.br/web/guest/indicadores-financeiros-educacionais/investimento-publicodireto-em-educacao-por-estudante-em-valores-nominais-por-nivel-de-ensino
} 
mensal. Atualizado o valor pelo INPC para janeiro de 2016, obtém-se o montante de R\$ $7.496,67^{8}$. Por essa linha de raciocínio, os gastos anuais com cada preso são mais de três vezes superiores aos custos médios por aluno na rede pública de ensino.

Posta as perspectivas de valores acerca dos custos por indivíduo no sistema educacional e penitenciário, a seguir nossa linha de argumentação, faz-se necessário a avaliação de eficácia entre os investimentos envolvidos. Como citado acima, a elasticidade entre o encarceramento e a diminuição do número de crimes é de 0.16 . Aliás, partiremos desse número médio encontrado, por termos como plausíveis as críticas debulhadas em torno da análise dos dados colhidos por autores que veem uma elasticidade mais significativa.

Em primeiro lugar, a elasticidade em economia, normalmente, é utilizada para explicar a relação das variáveis preço e demanda (KRUGMAN; WELLS, 2015, cap. 6). Segundo a lei da demanda há uma correlação negativa entre preço e demanda, ou seja, a medida em que o preço de um determinado produto ou serviço sobe a demanda por ele cai (KRUGMAN; WELLS, 2015, cap. 6). Daí a conclusão matemática de que a elasticidade preço-demanda é um número negativo (KRUGMAN; WELLS, 2015, cap. 6). É possível, de acordo com o entendimento alhures citado e com o qual assentimos, a aplicação desse conceito matemático-econômico para o estudo e análise do encarceramento em relação a diminuição do número de crimes violentos letais intencionais praticados.

Se partirmos de uma análise acerca da evolução da taxa de encarceramento no Brasil, é perceptível, entre os anos de 1990 e 2014, um aumento de certa de 400\% conforme dados do 9o anuário de segurança pública divulgado em 2015. De acordo com os dados obtidos, a taxa de encarceramento no Brasil, no ano de 1990, era de 105 presos por 100.000 habitantes com mais de dezoito anos. Já em 2014 essa taxa subira para 421 presos por 100.000 habitantes maiores de dezoito anos. Em 2011, por exemplo, essa taxa já era 374 presos por 100.000 habitantes com dezoito anos ou mais.

Outro dado importante é que o número de crimes letais intencionais em todo o país, no ano de 2011 , foi de 48.084 e no ano de 2014 foi $56.074^{9}$. Portanto, um aumento

\footnotetext{
${ }^{8}$ Cálculo segundo sítio do Banco Central. Disponível em: <https://www.bcb.gov.br/?CORRECAO>

${ }^{9}$ Dados obtidos no 7ํ e 9ㅇau anuários de segurança pública. Disponível em: <http://www.forumseguranca.org.br/>
} 
da ordem 16,616754\%. No mesmo período os gastos totais no Brasil com segurança pública passaram de $\mathrm{R} \$ 54.087 .445 .776,90$ em 2011 para $\mathrm{R} \$$ 59.305.236.705,05, portanto um aumento superior a 9\% . Nesse mesmo período a taxa de encarceramento subiu de 374 presos para 421 presos por cem mil habitantes maiores de dezoito anos, o que redundou em um acréscimo da ordem de 11,16\%.

De maneira que, pelos números citados acima, é possível concluir que a relação de elasticidade tanto entre a taxa de encarceramento, quanto em relação aos valores gastos com segurança pública e o número de crimes letais violentos é um número positivo. Ou seja, aparentemente, quanto maior o número de presos e maiores os gastos com segurança pública, o número de crimes violentos letais intencionais tende a aumentar. No que diz respeito ao encarceramento, mais especificamente, é plausível se dizer que a elasticidade é de aproximadamente $+0,67$ em relação aos crimes violentos letais intencionais.

Em relação a opinião pública aferida na pesquisa do Instituto Data Folha a que se fez referência, entre os dias 17 e 18 de junho de 2015,80\% dos entrevistados eram a favor da redução da maioridade penal para os crimes de homicídio, quando confrontados com a seguinte pergunta: "Para quais crimes você é a favor da redução da maioridade penal?". Justamente um tipo violento de crime que, aparentemente, não tem sua incidência afetada negativamente com o aumento da taxa de encarceramento.

Os dados de -0.16 citado por Donohue e referidos acima, apesar de não muito animadores, são negativos. Ou seja, existe, segundo estudos conduzidos no sistema de segurança pública americana, uma relação entre a taxa de encarceramento e diminuição de crimes, inclusive os violentos. No Brasil, por outro lado, os números fornecidos pelos anuários de segurança pública vão em sentido oposto, a saber, de que os aumentos das taxas de encarceramento senão fomentam os crimes violentos, não diminuem as chances deles ocorrerem.

Ao que parece, existe uma ideia de similaridade entre a punição de crimes violentos e a diminuição de sua prática, muito embora os dados da segurança pública no país revelem o contrário. Algo parecido, aliás, com a comparação feita por Kahneman e Tversky (1974) na qual os psicólogos dão grande valor a entrevistas de seleção, quando a literatura 
sobre o tema aponta a falibilidade do método. Isso é o que os autores denominam de ilusão de validade, na qual as pessoas selecionam determinadas soluções, aqui especificamente a punição ou encarceramento, pela similaridade com o input, em nosso caso, os altos números de crimes violentos letais intencionais.

Isto é, da mesma forma que os psicólogos entendem como efetivas as entrevistas de seleção para a escolha dos melhores candidatos, apesar das falhas apontadas para a técnica, as pessoas entrevistadas também entenderam como eficaz a punição de crimes violentos por adolescentes, apesar dos números da segurança pública sugerirem a ineficácia do encarceramento para a diminuição desta espécie de crime.

Uma das razões que se pode atribuir a esse aumento do comportamento criminoso violento, a despeito do acréscimo de esforço punitivo estatal revelado pelos números de segurança pública, pode ser a maneira que o comportamento criminoso habitual se sente recompensado pelo crime. Como exposto, a prática criminosa em si mesma seria recompensadora e, desta forma, a posterior punição por parte do Estado já não teria, em uma perspectiva behaviorista, o efeito desejado. Tal circunstância comportamental pode, ainda, oferecer uma explicação do porquê, apesar dos riscos de encarceramento se mostrarem significativamente maiores ao longo dos anos, já que a taxa proporcional à população aumentou significativamente, os indivíduos insistem no cometimento de rimes violentos.

Segundo os estudos mencionados por Flora (2004, p. 182), o criminoso pode se relacionar com a prática do crime de maneira muito similar a do adicto com as substâncias entorpecentes. De tal sorte, que o prazer na prática criminosa, quando posto na equação da função de utilidade pode exacerbar a grandeza desta, a ponto de os riscos parecerem aceitáveis sob a ótica do criminoso.

De outro lado, a educação em tempo integral demonstrou eficiência significativa na diminuição das práticas criminosas, de acordo com a experiência chilena acima mencionada. Além da diminuição da prática criminosa, haveria de se aglutinar ganhos outros, como a redução da gravidez na adolescência e a perspectiva de aumento de renda e diminuição das chances de desemprego (MENEZES-FILHO, 2001). Já em relação aos custos para sociedade, uma comparação entre o valor gasto com um preso no sistema 
federal (DEPEN) e um estudante, pelos dados obtidos e mencionados acima, é possível afirmar que é cerca de $330 \%$ mais caro a manutenção de um indivíduo no presídio do que na escola.

Se por um lado a mensuração dos efeitos das perdas podem apresentar distorções em relação a teoria do prospecto, inclusive pelos argumentos biopsicológicos acima expostos, haja vista que os estudos indicam um comportamento do criminoso em relação ao crime próximo ao adicto em substâncias entorpecentes, por outro lado a realidade de ganho de renda proporcionada pela educação formal, pode alterar a ideia de utilidade do crime para o indivíduo. Em outras palavras, o ponto de partida do indivíduo com maior escolaridade e, portanto, chances no mercado de trabalho, seria substancialmente maior e, por outro lado, os ganhos com uma atividade criminosa, a princípio, não lhe pareceria tão atraente a ponto de compensar os riscos.

Ainda em termos educacionais, a equação proposta por Becker, segundo a qual as influências sociais teriam o condão de alterar a função de utilidade de um determinado bem, também revela uma explicação plausível do porquê de adolescentes inseridos em tempo integral na escola praticarem menos crimes. É preciso considerar que em um ambiente escolar os pares do adolescente não estariam, normalmente, entregues ao cometimento de crimes e que os adolescentes estariam sob a supervisão de um adulto a maior parte do tempo. Em outras palavras, a escola exerceria uma influência social contrária a prática criminosa e, portanto, diminuiria a função de utilidade do crime.

\section{CONCLUSÕES}

Apesar da indignação que a maioria das pessoas manifesta com a ação do Estado na prevenção e repressão a crimes e a exigência de medidas mais severas para a contenção de tal prática, no que diz respeito aos crimes violentos letais intencionais, os dados da segurança pública demonstram que um aumento no aparato de segurança pública ou na taxa de encarceramento não são úteis.

O aumento do número de crimes violentos letais intencionais nos últimos anos foi acompanhado por acréscimos nos gastos com segurança pública e nas taxas de encarceramento que de 1990 até 2014 subiram aproximadamente 400\%, sem que se 
revelasse, esse aumento, apto a diminuir a prática dos crimes mencionados. Pelo contrário, os números apontam um aumento na prática de crimes violentos letais intencionais.

A visão de que o encarceramento por si ou acompanhado de maiores gastos com segurança pública são eficazes para o combate destes crimes, a princípio, revela-se um erro. De tal sorte que a redução da maioridade penal, embora apoiada por oitenta e sete por cento da população, segundo a pesquisa já mencionada, não se revela a melhor escolha aos interesses da sociedade, incluindo, obviamente, os apoiadores de tal medida. Um aumento nas taxas de encarceramento, na verdade, pode resultar em um acréscimo nos números de crimes violentos letais intencionais, ou seja, ter um efeito inverso ao desejado e esperado pela população. Além do aumento de gastos com o comprometimento de outras áreas da atuação do Estado, também consideradas sofríveis e essenciais, como a saúde e a educação.

Aliás, a educação, também segundo os estudos mencionados no capítulo 2, revelouse mais eficaz para a redução da prática criminosa nos meios urbanos do que o encarceramento. Mesmo em se tratando de crimes violentos, houve uma redução, pela experiência chilena com a educação, da ordem de $12 \%$ na prática de crimes violentos, com um aumento de $20 \%$ do sistema de ensino integral. Como no Brasil esse sistema ainda não foi adotado como regra, não se poderia mensurar os efeitos sobre a criminalidade violenta, no entanto, em uma perspectiva econômica comportamental é factível crer que pessoas com acesso a mais educação formal e, por consequência, aptas a postos de trabalho melhores remunerados, avaliarão os riscos de perda com a prática criminosa como sendo significativamente maiores do que aqueles que não possuem essa perspectiva.

\section{REFERÊNCIAS}

AGNEW, Robert. A general strain theory of community differences in crime rates. Journal of research in crime and delinquency, v. 36, n. 2, p. 123-155, 1999.

AGUIAR, Júlio César. O direito como sistema de contingências sociais. Revista da Faculdade de Direito UFG, V. 37, n. 02, p. 164 - 195, jul. /dez. 2013.

ALVAREZ, Alejandro Bugallo. Análise econômica do direito: contribuições e desmistificações. Revista Direito, Estado e Sociedade, n. 29, 2014. 
AZRIN, Nathan H.; HOLZ, William C. Punishment. Operant behavior: aeas of research and application, p. 380-447, 1966.

BAR-HILLEL, Maya; NETER, Efrat. How alike is it versus how likely is it: A disjunction fallacy in probability judgments. Journal of Personality and Social Psychology, v. 65, n. 6, p. 1119, 1993.

BECKER, Gary S. Crime and punishment: An economic approach. In:Essays in the economics of crime and punishment. NBER, p. 1-54, 1974.

2013.

. The economic approach to human behavior. University of Chicago press,

BECKER, Gary Stanley; MURPHY, Kevin M. Social economics: Market behavior in a social environment. Harvard University Press, 2009. Edição Kindle.

BERTHELON, Matias E.; KRUGER, Diana I. Risky behavior among youth: Incapacitation effects of school on adolescent motherhood and crime in Chile. Journal of public economics, v. 95, n. 1, p. 41-53, 2011.

BINNING, Kevin R. et al. Going along versus getting it right: The role of self-integrity in political conformity. Journal of Experimental Social Psychology, v. 56, p. 73-88, 2015.

BROWN, Charity; SCHAEFER, Alexandre. The effects of conformity on recognition judgements for emotional stimuli. Acta psychologica, v. 133, n. 1, p. 38-44, 2010.

BUONANNO, Paolo; LEONIDA, Leone. Non-market effects of education on crime: Evidence from Italian regions. Economics of Education Review, v. 28, n. 1, p. 11-17, 2009.

COOTER, Robert. ULEN, Thomas. Direito \& economia. Tradução Luís Marcos Sander, Francisco Araújo Costa. 5a ed. Porto Alegre: Bookman, 2010.

DONOHUE, John; SIEGELMAN, Peter, Allocating resources among prisons and social programs in the battle against crime. Faculty Scholarship Series, 1998. Paper 51.

DOOMEN, Jasper. Salvaging law and economics. Quality \& Quantity, v. 47, n. 4, p. 19431956, 2013.

FLORA, Stephen Ray. The power of reinforcement. State University of New York Press, 2004.

HOVENKAMP, Herbert. Rationality in law and economics. Geo. Wash. L. Rev., v. 60, p. 293, 1991.

JOLLS, Christine; SUNSTEIN, Cass R. Debiasing through law. National Bureau of Economic Research, 2005.

JOOLS, Christine; SUSTEIN, Cass R.; THALER, Richard. A Behavioral approach to la wand economics. Stanford Law Review, vol. 50, p. 1471-1529.

KAHNEMAN, Daniel. A perspective on judgment and choice: mapping bounded rationality. American psychologist, v. 58, n. 9, p. 697, 2003.

KAHNEMAN, Daniel; FREDERICK, Shane. Representativeness revisited: Attribute substitution in intuitive judgment. Heuristics and biases: the psychology of intuitive judgment, v. 49, 2002. 
KAHNEMAN, Daniel; TVERSKY, Amos. Prospect Theory: An Analysis of Decision under Risk. The Econometric Society, v. 47, n. 2, p. 263-292, Mar. 1979.

Extensional versus intuitive reasoning: The conjunction fallacy in probability judgment. Psychological review, v. 90, n. 4, p. 293, 1983.

TVERSKY, Amos; KAHNEMAN, Daniel. Judgment under uncertainty: Heuristics and biases. science, v. 185, n. 4157, p. 1124-1131, 1974.

KRUGMAN, Paul R.; Wells, Robin. Microeconomia: uma abordagem moderna. 3a ed. Rio de Janeiro: Elsevier, 2015

LEVITT, Steven D.; LIST, John A. What do laboratory experiments measuring social preferences reveal about the real world?. The Journal of Economic Perspectives, v. 21, n. 2, p. 153-174, 2007.

LEVITT, Steven D. The effect of prison population size on crime rates: Evidence from prison overcrowding litigation. National Bureau of Economic Research, 1995.

LOCHNER, Lance. Education, Work, and Crime: A Human Capital Approach. International Economic Review, v. 45, n. 3, p. 811-843, 2004.

. Education policy and crime. In: Controlling crime: strategies and tradeoffs. University of Chicago Press, p. 465-515, 2010.

LOCHNER, Lance; MORETTI, Enrico. The effect of education on crime: Evidence from prison inmates, arrests, and self-reports. National Bureau of Economic Research, 2001.

LOPES JR, Jair; MATOS, Maria Amélia. Controle pelo estímulo: aspectos conceituais e metodológicos acerca do controle contextual. Psicologia: Teoria e Pesquisa, v. 11, n. 01, p.33-39, jan./abr. 2012.

LYNG, Stephen. A Social Psychological Analysis of Voluntary Risk-Taking.Understanding Deviance: Connecting Classical and Contemporary Perspectives, v. 219, 2014.

MADJD-SADJADI, Zagros. The economics of crime. Business expert Press, 2013. Edição kindle, posição 651.

MARVELL, Thomas B.; MOODY JR, Carlisle E. Prison population growth and crime reduction. Journal of Quantitative Criminology, v. 10, n. 2, p. 109-140, 1994.

MATSUEDA, Ross L.; KREAGER, Derek A.; HUIZINGA, David. Deterring delinquents: A rational choice model of theft and violence. American Sociological Review, v. 71, n. 1, p. 95-122, 2006.

SCHWARZ, Norbert; VAUGHN, Leigh Ann. The availability heuristic revisited: Ease of recall and content of recall as distinct sources of information. In: GILOVICH, Thomas; GRIFFIN, Dale W. e KAHNEMAN, Daniel. Heuristics and Biases: The Psychology of Intuitive Judgment. New York. Cambridge University Press, 2002. pp. 103-119. http://dx.doi.org/10.1017/CBO9780511808098.007

O'DOHERTY, J. et al. Abstract reward and punishment representations in the human orbitofrontal cortex. Nature Neuroscience, v. 4, n. 1, p. 95, 2001.

POSNER, Richard A. Rational choice, behavioral economics, and the law. Stanford Law Review, p. 1551-1575, 1998. 
Para além do direito. Martins Fontes, São Paulo, 2009, p. 155-179.

SABATES, Ricardo; FEINSTEIN, Leon. Effects of government initiatives on youth crime. Oxford Economic Papers, p. gpm038, 2007.

SCHNEIDER, Susan. The science of consequences: how they affect genes, change the brain and impact our world. New York, 2012.

SKINNER, Burrhus Frederic. The behavior of organisms: an experimental analysis. B. F. Skinner Foundation, 1938.

Science and human behavior. B. F. Skinner Foundation, 1954.

About behaviorism. Vintage, New York, 2011.

TODOROV, João Cláudio. Quem tem medo de punição? Revista Brasileira de Terapia Comportamental e Cognitiva, v. 3, n. 1, p. 37-40, 2001.

TOR, Avishalom. The methodology of the behavioral analysis of law. Haifa Law Review, v. 4, p. 237, 2008.

VALENZUELA, Juan Pablo. Partial evaluation of a big reform in the Chilean education system: From a half day to a full day schooling. University of Michigan Doctoral Dissertation, 2005.

WALTERS, Caroline E.; KENDAL, Jeremy R. An SIS model for cultural trait transmission with conformity bias. Theoretical Population Biology, v. 90, p. 56-63, 2013.

WOOD, Peter B. et al. Nonsocial reinforcement and habitual criminal condut: in the extension of learning theory. Criminology, v. 35, n. 2, p. 335-366, 1997.

WATSON, John B. Psychology as the behaviorist views it. Psychological Review, n. 20, 158177. 1913

WOLFE, Barbara L. et al. Social and nonmarket benefits from education in an advanced economy. In: Conference series-federal reserve bank of boston. Federal Reserve Bank of Boston; 1998, 2002. p. 97-131.

AGUIAR, Julio Cesar; GOMES, Carrel Ypiranga Benevides; TABAK, Benjamin Miranda. Redução da maioridade penal em relação aos crimes violentos: uma análise econômicocomportamental. RBSD - Revista Brasileira de Sociologia do Direito, v. 5, n. 1, p. 143-163, jan./abr. 2018.

Recebido em: 16/08/2017

Aprovado em: 01/09/2017 